\title{
A Study on the Effects of Countermeasures for Vibrating Tool Workers Using an Impact Wrench
}

\author{
Yoko AIBA ${ }^{1,4 *}$, Satoshi OHSHIBA ${ }^{1}$, Hisayoshi ISHIZUKA ${ }^{2}$, Kunihiro SAKAMOTO ${ }^{1}$, \\ Ikuharu MORIOKA ${ }^{3}$, Kazuhisa MIYASHITA ${ }^{3}$ and Hirotoshi IWATA ${ }^{4}$
}

\author{
${ }^{1}$ Japan Industrial Safety and Health Association, Osaka Occupational Service Center, 2-3-8, Tosabori, Nishi-ku, \\ Osaka 550-0001, Japan \\ ${ }^{2}$ Japan Industrial Safety and Health Association, Hokkaido Regional Safety and Health Service Center, Minami \\ 19-jo, Nishi 9-chome, Chuo-ku, Sapporo 064-0919, Japan \\ ${ }^{3}$ Department of Hygiene, Wakayama Medical University, School of Medicine, 811-1, Kimiidera, Wakayama \\ 641-0012, Japan \\ ${ }^{4}$ Department of Hygiene, Gifu University, School of Medicine, 40 Tsukasa-machi, Gifu 500-8705, Japan
}

Received July 28, 1999 and accepted August 25, 1999

\begin{abstract}
The aims of this study were (1) to measure frequency-weighted vibration acceleration and (2) to study the effects of introducing a vibration-proof impact wrench on VWF in workers. The subject pool was $\mathbf{3 8 3}$ male workers who were regularly using an impact wrench and taking special medical examinations for vibration syndrome in a factory from 1982 to 1999 . The prevalence of workers with VWF increased gradually after 1982 , reached a peak value $(4.8 \%)$ in 1986 , gradually decreased after 1987, and disappeared in 1994. Sixteen subjects who had had VWF at least one time during the observation period were selected for this study. The stages of VWF were at stage I on the Stockholm Workshop scale in all subjects. After the vibration-proof impact wrench was introduced in 1986, the vibration acceleration of the impact wrench measured on the handle decreased from $8.6-11.1 \mathrm{~m} / \mathrm{s}^{2}$ to $5.1-7.1 \mathrm{~m} / \mathrm{s}^{2}$. The actual time per day that subjects were assumed to use the impact wrench was 108 minutes. The subjects actually used an impact wrench more than the occupational exposure limit allowed. However, VWF disappeared after the introduction of a vibrationproof impact wrench. This might have resulted from the combined effect of introducing the vibrationproof impact wrench and certain countermeasures that were taken against cold working environments.
\end{abstract}

Key words: Vibration syndrome, VWF, Raynaud's phenomenon, Frequency-weighted vibration acceleration, Exposure time, Countermeasures, Impact wrench

\section{Introduction}

Vibration diseases caused by occupational exposure to vibration of hand tools is called the hand-arm vibration syndrome (HAVS). Symptoms result from various disturbances in the peripheral circulation, peripheral nerves $^{1-3)}$, and the muscles, bones, and joints of the hands

*To whom correspondence should be addressed. and arms. The most prominent HAVS disease is vibrationinduced white finger (VWF). The prevalence of VWF sharply increased as various types of vibration tools, including chain saws, spread to a wide range of industrial fields in the latter half of the 1960 ' $\mathrm{s}^{4}$. To reduce the prevalence of VWF among workers using chain saws, countermeasures such as limiting the working hours were initiated in the 1970 's ${ }^{5}$. Simultaneously, technical improvements in vibration tools also started to decrease the vibration level of the vibration 
Table 1. Number of in a factory from 1982 to 1999

\begin{tabular}{rrrrrrrrrr}
\hline & '82 & '83 & '84 & '85 & '86 & '87 & '88 & '89 & '90 \\
\hline $\mathrm{N}$ & 366 & 349 & 239 & 265 & 188 & 226 & 225 & 217 & 198 \\
\hline & & & & & & & & & \\
\hline & '91 & '92 & '93 & '94 & '95 & '96 & '97 & '98 & '99 \\
\hline $\mathrm{N}$ & 187 & 182 & 182 & 175 & 166 & 151 & 134 & 128 & 123 \\
\hline
\end{tabular}

tools ${ }^{6-8)}$. Some reports ${ }^{9,10)}$ have already noted a decrease in VWF in recent years. However, little information is available on the effects of countermeasures for workers using an impact wrench in longitudinal studies.

Our preliminary study ${ }^{11}$ reported that various countermeasures that have been taken on several occasions for workers using an impact wrench have been effective in decreasing symptoms and prevalence of abnormal findings in special medical examinations on the vibration syndrome in a factory. The specific countermeasures taken consisted of introducing a vibration-proof impact wrench and keeping working environments warm. We next assumed that introducing a vibration-proof impact wrench would be an effective factor in decreasing the prevalence of VWF. In this study, we focused on the vibration value of an impact wrench. We measured the frequency-weighted vibration acceleration of an impact wrench and studied the effects of introducing a vibration-proof impact wrench on VWF prevalences in workers.

\section{Subjects and Methods}

\section{Subjects}

The subjects were all workers occupationally using an impact wrench in a manufacturing factory for electric-light poles in Mie Prefecture, Japan, from 1982 to 1999 (Table 1). These workers used an impact wrench to screw or unscrew bolts in the processes of molding and unmolding an electriclight pole to pour concrete. The work times and work conditions for workers using an impact wrench were unvaried during the observation period. Special medical examinations for vibration syndrome began in 1982. A total of 383 male workers were selected as subjects for the special medical examinations for vibration syndrome. The percentage of workers who took the special examination was close to $100 \%$ of the workers using an impact wrench in their daily tasks.

Each subject was asked to complete a questionnaire on work histories, medical histories, and subjective symptoms, including VWF. To identify VWF, a medical doctor asked the subject for detailed information regarding the site, the frequency, and the factors inducing VWF. Furthermore, the medical doctor confirmed the VWF diagnosis by showing the subject a photograph of typical VWF conditions.

Eighteen of the 383 members of the subject pool were identified as having VWF. A subject who had a hand injury and a subject having Buerger's disease were excluded, so that for this study, 16 workers were selected as subjects who had had VWF at least one time during the observation period.

\section{Stages of VWF}

The stages of VWF were set on the Stockholm Workshop scale for the classification of cold-induced Raynaud's phenomenon in the hand-arm vibration syndrome (Table 2). The subjects were evaluated using the highest grade of VWF that they attained during the observation period.

\section{Frequency-weighted vibration acceleration}

The vibration acceleration of an impact wrench was measured on its handle while a subject was unscrewing a bolt. The vibration pick-up, a heavy $(29.3 \mathrm{~g})$ triaxes piezoelectric type (PV-93T, Rion Co.), was mounted firmly with pair steel belts (width: $6.4 \mathrm{~mm}$, thickness: $0.5 \mathrm{~mm}$ ) and a fitting base on a handle of the object tool (1 point or more measured per tool). The vibration acceleration signals on the three axes were measured simultaneously with a vibration transducer ( $3 \mathrm{ch}, \mathrm{VM}-19 \mathrm{~A}$, Rion Co.), and were recorded with a DAT type data recorder $(4 \mathrm{ch}, \mathrm{RD}-120 \mathrm{~T}$, Teac Co.) for about five minutes.

Recorded data were analyzed with a one-third octave band real-time analyzer (SA-27, Rion Co.) for about ninety seconds while an impact wrench was in operation. The overall and the frequency-weighted vibration acceleration in r.m.s were computed. The vibration acceleration of vibration tools were determined by the ISO 5349 guidelines ${ }^{12)}$ and Japanese standards (JIS B 4900) ${ }^{13}$.

Measurements were also conducted for a formerly used tool (16-WE, YUTANI Co.) in 1994 and a subsequent tool (16-WK, YUTANI Co.) in 1998. 
Table 2. The Stockholm Workshop scale for the classification of cold-induced Raynaud's phenomenon in the hand-arm vibration syndrome

\begin{tabular}{|c|c|c|}
\hline Stage & Grade & Description \\
\hline 0 & & No attacks \\
\hline 1 & Mild & Occasional attacks affecting only the tips of one more fingers \\
\hline 2 & Moderate & $\begin{array}{l}\text { Occasional attacks affecting distal and middle (rarely also } \\
\text { proximal) phalanges of one or more fingers }\end{array}$ \\
\hline 3 & Severe & Frequent attacks affecting all phalanges of most fingers \\
\hline 4 & Very severe & As in stage 3 , with trophic skin changes in the finger tips \\
\hline
\end{tabular}

The staging is made separately for each hand. In the evaluation of the subjects, the grade of the disorder is indicated by the stages of both hands and the number of affected fingers on each hand; example: " $2 \mathrm{~L}(2) / 1 \mathrm{R}(1)$ ", “-/3R(4)", etc.

\section{Exposure time}

We recorded a half-day's work for each worker using an impact wrench by videotape in 1998 . The videotape was used to compute the actual exposure time (time spent using an impact wrench) during the unmolding of an electric-light pole. The exposure time was computed from the time a subject switched on an impact wrench to the time the subject switched it off. Next, the actual exposure time per day was computed based on the number of poles produced a day.

\section{Results}

The prevalence of workers with VWF was calculated among workers using an impact wrench from 1982 to 1999 (Fig. 1). The prevalence of VWF was $1.7 \%$ in 1982 . This percentage increased gradually after 1982 and reached its peak value (4.8\%) in 1986, when a vibration-proof impact wrench was introduced. The figure gradually decreased in 1987 and thereafter, disappearing altogether in 1994.

The Stockholm Workshop scale classified all subjects as having stage I. No subject was found to have stage II, III or IV.

Annual trends in the occurrence of VWF are summarized in Fig. 2. Subjects used the impact wrench throughout the observation period, even when they had VWF. In five subjects, VWF had already disappeared before the introduction of the vibration-proof impact wrench. In two subjects, VWF appeared after the introduction of the vibration-proof impact wrench, but it continued only for one or two years. In nine subjects, VWF disappeared after the introduction of the vibration-proof impact wrench.

The overall and the vibration acceleration spectra in the three axes are shown in Fig. 3. In the z-axis (Fig. 3a), the overall was $8.6 \mathrm{~m} / \mathrm{s}^{2}$ for the formerly used tool and $7.1 \mathrm{~m} / \mathrm{s}^{2}$ for the subsequent tool. The subsequent tool had a lower

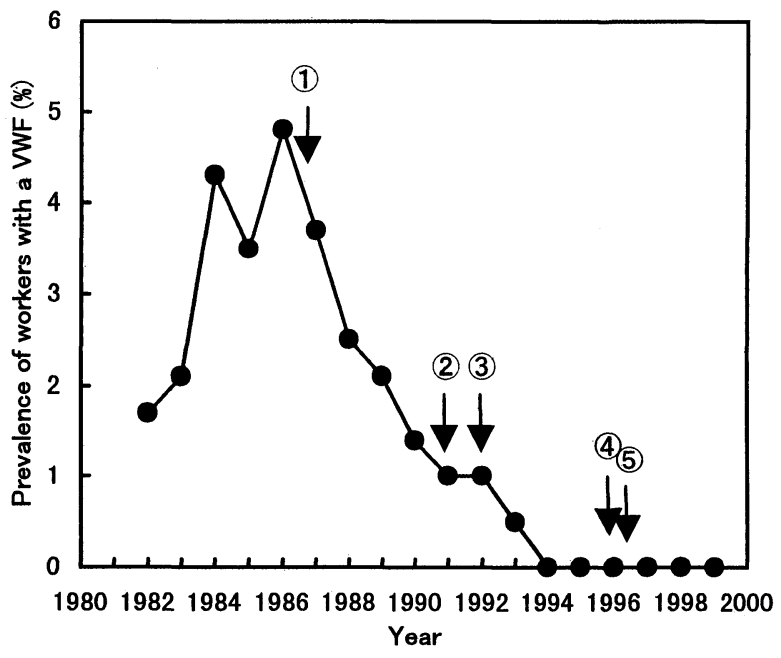

Fig 1. Prevalence of workers with VWF among workers using an impact wrench from 1982 to 1999.

Arrows refer to the following countermeasures: (1) introducing a vibration-proof impact wrench (2) A curtain for protection against the cold was fitted at an entrance of a workshop to protect against the outdoors (3) A hot well was set up for washing hands in warm water (4)An impact wrench with an air-heated warm handle was introdicisd to warm hands while working (5)A curtain for protection against the cold was fitted at an entrance of another workshop to protect against the outdoors.

vibration acceleration at frequencies of 8 to $25 \mathrm{~Hz}, 630 \mathrm{~Hz}$, and higher. In the y-axis (Fig. 3b), the overall was $8.9 \mathrm{~m} / \mathrm{s}^{2}$ for the formerly used tool and $5.5 \mathrm{~m} / \mathrm{s}^{2}$ for the subsequent tool. The subsequent tool had a lower vibration acceleration at frequencies of 8 to $50 \mathrm{~Hz}, 80 \mathrm{~Hz}$, and higher. In the $\mathrm{x}$ axis (Fig. 3c), the overall was $11.1 \mathrm{~m} / \mathrm{s}^{2}$ for the formerly used tool and $5.1 \mathrm{~m} / \mathrm{s}^{2}$ for the subsequent tool. The subsequent tool had a lower vibration acceleration at frequencies of 8 to $31.5 \mathrm{~Hz}, 125 \mathrm{~Hz}$, and higher. 


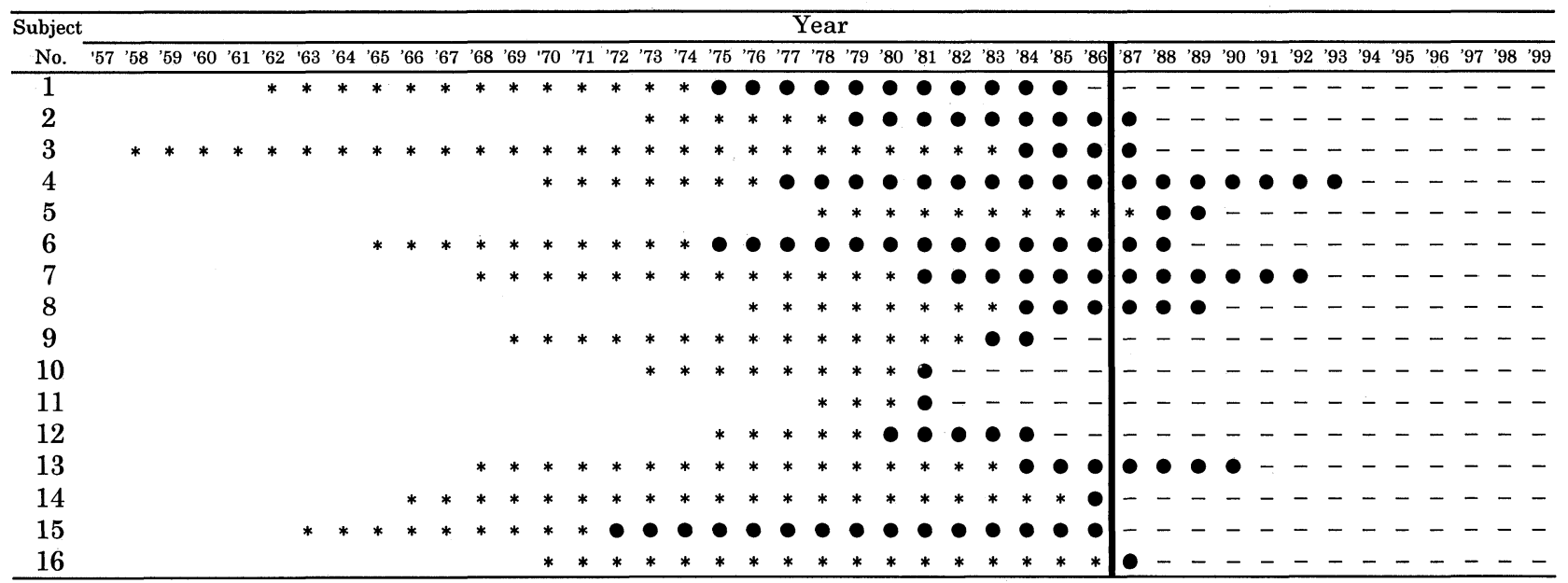

Fig. 2. Annual trends in the occurrence of VWF.

*: Exposure period; O: Occurrence of VWF, - : Disappearance of VWF. Subjects used the impact wrench throughout the observation period, even when they had VWF. A vibration-proof impact wrench was introduced in 1986.
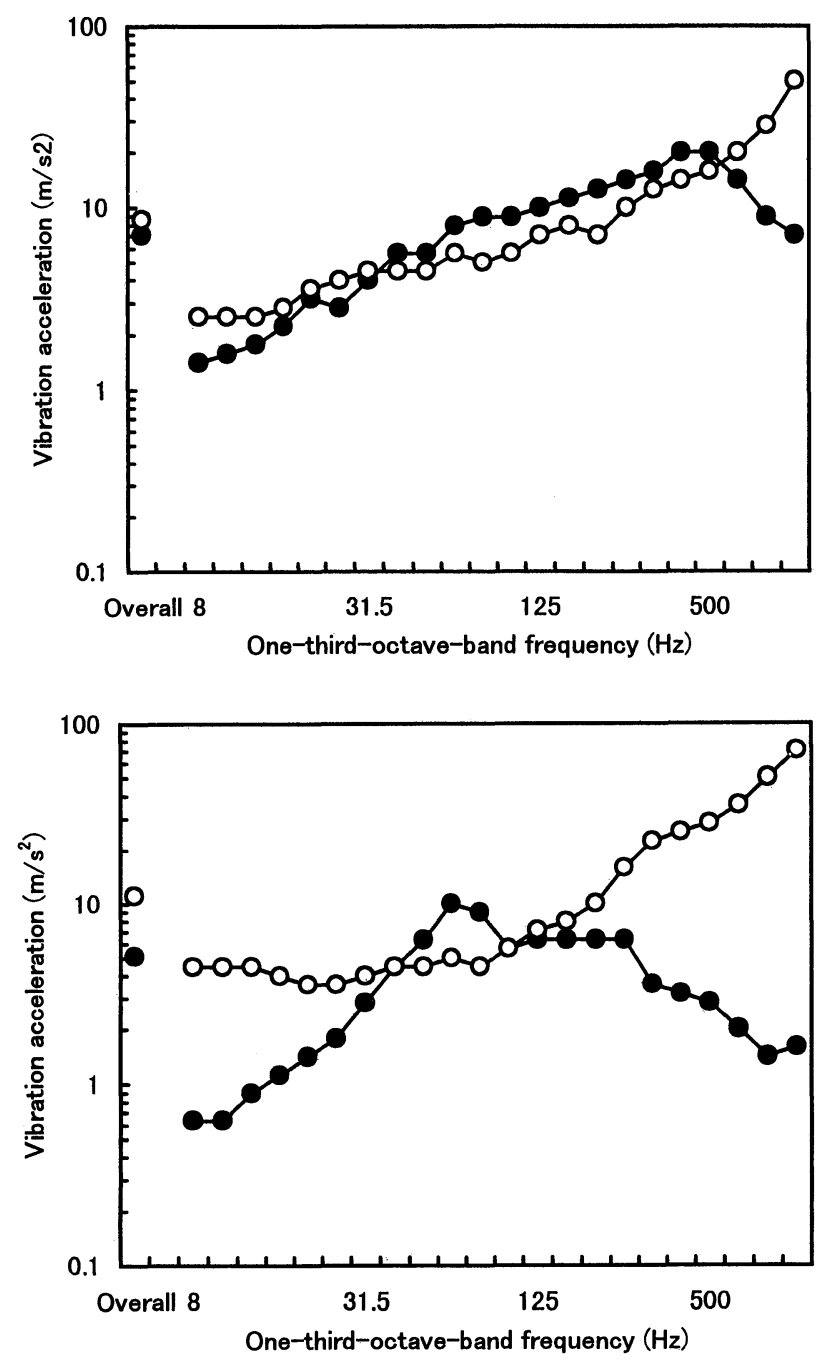

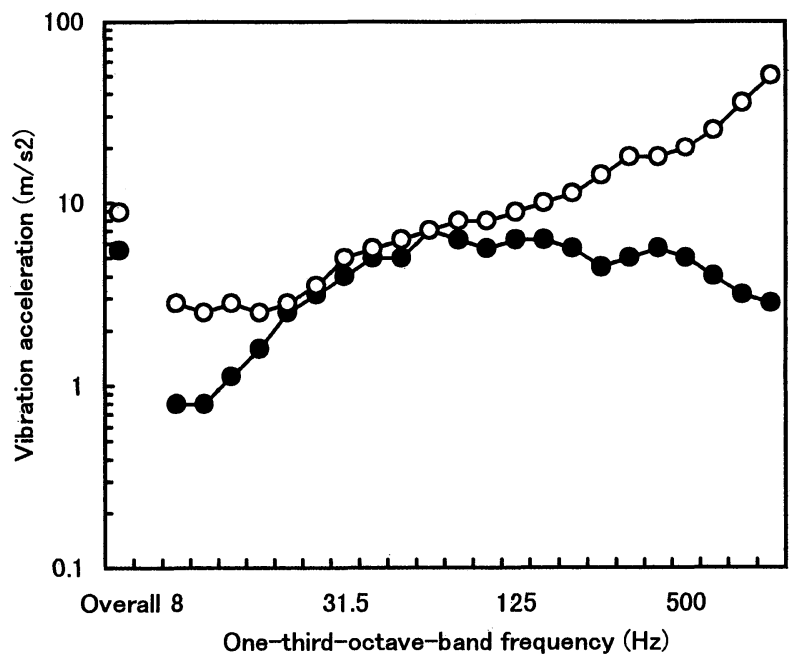

\begin{tabular}{l|l} 
Fig. 3a & Fig. 3b \\
\hline Fig. 3c &
\end{tabular}

Fig. 3a. Overall and vibration acceleration spectra for the formerly used (- $\left.\bigcirc_{-}\right)$and the subsequent impact wrench (- -$)$in the z-axis.

Fig. 3b. Overall and vibration acceleration spectra for the formerly used (- $\left.\bigcirc_{-}\right)$and the subsequent impact wrench (- - ) in the $y$-axis.

Fig. 3c. Overall and vibration acceleration spectra for the formerly used (- $\left.\bigcirc_{-}\right)$and the subsequent impact wrench (- - ) in the $x$-axis. 
Table 3. Frequency-weighted vibration accelerations of the formerly used tool and the subsequent tool.

\begin{tabular}{lccc}
\hline & \multicolumn{3}{c}{ frequency-weighted vibration acceleration $\left(\mathrm{m} / \mathrm{s}^{2}\right)$} \\
\cline { 2 - 4 } & $\mathrm{a}_{\mathrm{hwx}}$ & $\mathrm{a}_{\text {hwy }}$ & $\mathrm{a}_{\text {hwz }}$ \\
\hline The formerly used tool & 11.1 & 8.9 & 8.6 \\
The subsequent tool & 5.1 & 5.5 & 7.1 \\
\hline
\end{tabular}

The frequency-weighted vibration accelerations of the formerly used tool and the subsequent tool are summarized in Table 3. The frequency-weighted vibration acceleration of the formerly used tool varied between $8.6 \mathrm{~m} / \mathrm{s}^{2}$ and 11.1 $\mathrm{m} / \mathrm{s}^{2}$, and that of the subsequent tool was between $5.1 \mathrm{~m} / \mathrm{s}^{2}$ and $7.1 \mathrm{~m} / \mathrm{s}^{2}$. The frequency-weighted vibration accelerations of the subsequent tool were lower than that of the formerly used tool in three axes. The dominant axis in the formerly used tool was the $\mathrm{x}$-axis and that of the subsequent tool was the $\mathrm{z}$-axis.

The actual exposure time for a pole, computed from videotape was 92.6 seconds. The number of poles produced a day was 70 on average. Thus, the actual exposure time per day was 108 minutes. The number of poles produced a day varied from 66 to 76 , so that the actual exposure time per day varied from 102 minutes to 117 minutes.

\section{Discussion}

Countermeasures for workers using the impact wrench started in 1986 at the factory. These countermeasures consisted of introducing a vibration-proof impact wrench and keeping warm in working environments.

The impact wrench was improved in the following process in 1986: rubber was inserted between the vibrating core body and the operating handle, and the suspension handle was covered with rubber. Consequently, the frequency-weighted vibration acceleration was decreased from $8.6-11.1 \mathrm{~m} / \mathrm{s}^{2}$ to $5.1-7.1 \mathrm{~m} / \mathrm{s}^{2}$. In this study, the prevalence of VWF decreased after introducing the vibration-proof impact wrench in 1986, and VWF disappeared in 1994. This may be due to the decrease in vibration acceleration provided by the new, vibration-proof impact wrench.

Improvement on a vibration tool involves the reduction of the exposure of workers' hands to vibration. Technical improvements in the motors of vibration tools and the introduction of a vibration-proof vibration tool has drastically reduced the frequency-weighted vibration acceleration in the handles of some vibration tools. The frequency-weighted vibration acceleration in the handle of a chain saw, for example, was reduced from $10-20 \mathrm{~m} / \mathrm{s}^{2}$ to $2-4 \mathrm{~m} / \mathrm{s}^{27-9)}$. Longitudinal studies on the effect of changes in vibration acceleration of a chain saw showed decreases in the prevalence of $\mathrm{VWF}^{9,10)}$.

Frequency components of $200 \mathrm{~Hz}$ were harmful to vessels ${ }^{14)}$. At the most harmful frequency component of $125 \mathrm{~Hz}^{12)}$, vibration acceleration decreased about $0.8 \mathrm{~m} / \mathrm{s}^{2}$ in the $\mathrm{x}$-axis (Fig. 3c). The frequency-weighted vibration acceleration of the subsequent tool decreased about $6 \mathrm{~m} / \mathrm{s}^{2}$ in the $\mathrm{x}$-axis (Table 3). Thus, we may conclude that the decreased occurrence of VWF resulted from the introduction of the vibration-proof impact wrench.

The total daily exposure time to hand-arm vibration was a mean value of about four hours a day in different factories ${ }^{15)}$. This exposure time of four hours a day is the recommended occupational exposure limit for hand-arm vibration exposure under the Japanese guidelines ${ }^{16}$. Mirbod ${ }^{15)}$ reported that following this occupational exposure limit would possibly reduce the occurrence of hand-arm vibration syndrome. In this study, the subjects were asked in the special medical examinations about the amount of time a day they spent using an impact wrench. The subjects answered four hours on the average. However, they actually used an impact wrench for less than two hours (108 minutes) a day.

Various improvements were made in the factory to keep the working environments warm. A curtain for protection against the cold was fitted at an entrance of a workshop to separate the working area from the outdoors (1991). A hot well was set up for washing hands in warm water (1992). An impact wrench with an air-heated warm handle was introduced to keep hands warm while working (1996). A curtain for protection against the cold was fitted at an entrance of another workshop to separate the working area from the outdoors (1996). It could be speculated that these improvements in the working conditions and the reduction of the vibration acceleration using the vibration-proof impact wrench are of considerable importance in controlling the vibration syndrome. Iwata reported ${ }^{17)}$ that the prevalence of VWF among workers using chain saws was lowered when they were protected against exposure to the cold.

The stages of VWF were mild in all subjects. This may also be an important factor in the disappearance of VWF.

VWF probably disappeared primarily as a result of the decrease in vibration level of the impact wrench. It should be noted that it is also necessary to regulate working environments with procedures such as protecting workers from exposure to cold to prevent the occurrence of VWF. 


\section{Acknowledgment}

The authors are grateful to Dr. Yoshiharu Yonekawa in the Division of Human Engineering, National Institute of Industrial Health, for revising the present manuscript. The results of the study were presented in the 7th Japan Group Meeting on Human Response to Vibration in July 1999 in Wakayama, Japan.

\section{References}

1) Taylor W (1974) Introduction, In: Vibration syndrome. ed. by Taylor W, 1-12, Academic, London.

2) Taylor W, Brammer AJ (1982) Introduction to proceedings of 3rd international conference on handarm vibration. In: Vibration effects on the hand and arm in industry. eds. by Brammer AJ, Taylor W, 1-12, Wiley, New York.

3) Taylor W, Pelmear PL, Pearson J (1974) Raynaud's phenomenon in forestry chain saw operators. In: The vibration syndrome. ed. by Taylor W, 121-39, Academic, London.

4) Miura $T$ (1975) Historical review of vibration syndrome due to vibrating tools in Japan from 1950's to 1960's. J Sci Labour 51, 459-78.

5) Saito K (1978) Prevention of the hand-arm vibration syndrome. Scand J Work Environ Health 13, 301-4.

6) Yamawaki $S$ (1977) Reduction of vibration in power saws in Japan. In: Proceedings of the international occupational hand-arm vibration conference. eds. by Wasserman DE, Taylor W, Curry MG, 209-17, National Institute for Occupational Safety and Health.

7) Pyykkö I, Farkkila M, Hoikkala M, Korhonen O, Nurminen M, Starck J (1981) Hand-arm vibration in the etiology of hearing loss in lumberjacks. Br J Ind Med, 38, 281-9.

8) Starck J (1984) High impulse acceleration levels in hand-held vibratory tools: An additional factor in the hazards associated with the hand-arm vibration syndrome. Scand J Work Environ Health 10, 171-8.

9) Taylor W, Pelmear OL, Hempstock TI, O' Connor DE, Kitchener JR (1975) A longitudinal study of Raynaud's phenomenon in chain saw operators. In: Vibration white finger in industry. eds. by Taylor W, Pelmear PL, 1520, Academic Press, London.

10) Pyykkö I, Korhonen O, Farkkila M, Stark J, Aatola $S$ (1982) A longitudinal study of the vibration syndrome in Finnish forestry workers. In: Vibration effects of the hand and arm in industry. eds. by Brammer AJ, Taylor W, 157-67, John Wiley \& Sons. New York.

11) Aiba Y, Ohshiba S, Sakamoto K, Morioka I, Miyashita K, Iwata H (1999) On the countermeasures for the workers operating to impact wrench and its effect in a factory. J Wakayama Med Soc (in Japanese) (in press).

12) International Organization for Standardization (1998) Mechanical vibration-Measurement and assessment of human exposure hand-transmitted vibration-Part 1 : General guidelines. ISO/CD 5349-1.

13) Japanese Industrial Standards Committee (1979) Method of measurement and description of handtransmitted vibration level. JIS B 4900.

14) Kotani A, Miyata S, Iwata $H$ (1974) Relationship between vibratory sense threshold and skin temperature. Jpn J Hyg 4, 459-62 (in Japanese).

15) Mirbod SM, Inaba R, Iwata $H$ (1992) A study on the Vibration-Dose Limit for Japanese Workers Exposed to Hand-Arm Vibration. Ind Health 30, 1-22.

16) Japan Society for Occupational Health (1997) Guidelines for the assessment of occupational exposure to hand-transmitted vibration (in Japanese).

17) Iwata H, Kasamatsu T, Miyashita K, Shiomi S (1980) A study on forestry workers with low prevalence rate of Raynaud's phenomenon. J Wakayama Med Soc 31, 351-5 (in Japanese). 